\title{
Characterization of the murf gene of the cyanobacterium Synechocystis sp. PCC 6803
}

\author{
Michael P. Malakhov, ${ }^{1,2}$ Dmitry A. Los, ${ }^{1}$ Hajime Wada, ${ }^{1} \dagger$ \\ Victor E. Semenenko ${ }^{2}$ and Norio Murata ${ }^{1}$
}

\begin{abstract}
Author for correspondence: Norio Murata. Tel: +81564 55 7600. Fax: +81564544866. e-mail:murata@nibb.ac.jp
\end{abstract}

1 Department of Regulation Biology, National Institute for Basic Biology, Myodaiji, Okazaki 444, Japan

2 Institute of Plant Physiology, Russian Academy of Sciences, Botanicheskaya 35 , Moscow 127276, Russia

\begin{abstract}
The murF gene encodes UDP-N-acetylmuramoyl-L-alanyl-D-glutamyl-meso-2,6diaminopimeloyl-D-Ala-D-Ala synthetase (EC 6.3.2.15), which catalyses the final step in the synthesis of UDP-N-acetylmuramoyl-pentapeptide, the precursor of murein. An open reading frame identified as the murf gene was found in the genome of the cyanobacterium Synechocystis sp. PCC 6803. The murf gene encodes a polypeptide of $\mathbf{4 5 4}$ amino acid residues with a predicted molecular mass of $48 \mathrm{kDa}$. The murf gene is present as a single-copy gene in the genome of Synechocystis sp. PCC 6803. The amino acid sequence deduced from the murf gene is $39 \%$ identical to that of the product of the murf gene of Escherichia coli. The cyanobacterial murf gene complemented a temperaturesensitive mutation in a murf-deficient strain of $E$. coli, restoring the mutant's ability to synthesize a cell wall and to survive at high sublethal temperatures.
\end{abstract}

Keywords: cell wall, cyanobacterium, murF gene, murein, Synecbocystis sp. PCC 6803

\section{INTRODUCTION}

The biosynthesis of the bacterial peptidoglycan known as murein is a complex process that consists of at least three major steps: (1) the synthesis of UDP- $N$-acetylmuramoylpentapeptide from UDP- $N$-acetylglucosamine in the cytoplasm; (2) the lipid cycle reactions, in which a final pentapeptide precursor is transferred from the cytoplasm to an existing peptidoglycan; (3) the formation of crosslinked polysaccharides and the cell wall saccule (Cooper, 1991; Rogers et al., 1980).

The murF gene of Escherichia coli (Parquet et al., $1989)$ encodes UDP- $N$-acetylmuramoyl-L-alanyl-D-glutamyl-meso-2,6-diaminopimeloyl-D-Ala-D-Ala synthetase (EC 6.3.2.15), which adds D-alanyl-D-alanine to UDP$\mathrm{N}$-acetylmuramoyl-L-alanine-D-glutamyl-meso-2,6-diaminopimelate (Michaud et al., 1987). This reaction is the last step in the chain of reactions in the synthesis of UDP- $N$-acetylmuramoyl-pentapeptide. Mutants of E. coli deficient in the $\operatorname{mur} F$ gene cannot synthesize a properly structured cell wall and lyse at high temperatures, such as $42{ }^{\circ} \mathrm{C}$, as a result of the impaired synthesis of peptidoglycan (Lugtenberg \& van Schijndel-van Dam, 1972; Maruyama et al., 1988).

†Present address: Department of Biology, Faculty of Science, Kyushu University, Ropponmatsu, Fukuoka 810, Japan.

The EMBL/GenBank/DDBJ accession number for the nucleotide sequence data reported in this paper is X62437 (SSMURFA).
The cell surface of $E$. coli has been well characterized (Cooper, 1991), but the cell surface of cyanobacteria has not been characterized to the same extent. The presence of an outer membrane in cyanobacteria (Drews \& Weckesser, 1982) suggests that cyanobacterial cell walls might be similar to those of Gram-negative bacteria. However, cyanobacterial cell walls react positively in the Gram reaction (Jürgens $e t a l ., 1985$ ). The thickness of the murein layer of cyanobacterial cell walls (Weckesser \& Jürgens, 1988) and the degree of cross-linkage in peptidoglycan are similar to those found in Gram-positive bacteria (Jürgens et al., 1983; Jürgens \& Weckesser, 1986). Jürgens et al. (1983) concluded that cyanobacteria have developed their own particular organization of cell walls, which differs from that of the typical cell walls of both Gram-negative and Gram-positive bacteria.

Here we present data on the structure and expression of the $\operatorname{murF}$ gene from the unicellular cyanobacterium Synechocystis sp. PCC 6803.

\section{METHODS}

Strains and culture conditions. Competent cells of E. coli JM109 for subcloning of DNA were obtained from Takara (Kyoto, Japan). A high-temperature-sensitive $m u r F$-deficient strain, E. coli JE6607 [ $\mathrm{F}^{-}$, murF(Ts), $\Delta$ pro-lac, thi] (Maruyama et al., 1988), was obtained from the National Institute of Genetics (Mishima, Japan). Cells of E. coli JE6607 were grown at $30^{\circ} \mathrm{C}$ in Luria-Bertani (LB) medium (Sambrook et al., 1989). The cells were rendered competent with $\mathrm{CaCl}_{2}$ as described by Sambrook 
et al. (1989). The cyanobacterium, Synechocystis sp. PCC 6803, was obtained from the Pasteur Culture Collection (Paris, France). Synechocystis sp. PCC 6803 was cultivated at $34^{\circ} \mathrm{C}$ under photoautotrophic conditions in BG11 medium (Stanier et al., 1971), with continuous aeration with air containing $1 \%(\mathrm{v} / \mathrm{v})$ $\mathrm{CO}_{2}$ as previously described (Wada \& Murata, 1989).

Analysis of DNA sequence. The plasmid p'TZ19R/8 kbp, carrying a $7 \cdot 4 \mathrm{~kb}$ fragment of the genomic DNA of Synechocystis sp. PCC 6803, was obtained as described previously (Wada et al., 1990). The full-length insert was excised from the plasmid by digestion with EcoRI restriction endonuclease and was recloned into pBluescript II $\mathrm{KS}(+)$ (Stratagene). The resultant plasmid was designated pES17. The nucleotide sequence of the region downstream of the des $A$ gene, which encodes the $\Delta 12$ desaturase (Wada et al., 1993), was determined by the dideoxy chaintermination method (Sanger et al., 1977), with deletions by exonuclease III and mung bean exonuclease (both from New England Biolabs) and with synthetic oligonucleotides as sequencing primers. The computer analysis of the sequence data was performed using the PCGene program package for personal computers (IntelliGenetics). The amino acid sequences were aligned according to the algorithm of Needleman \& Wunsch (1970).

Southern blot hybridization. Genomic DNA was isolated from Synechocystis sp. PCC 6803 by the method of Williams (1988). The DNA was digested with HindIII, DraI, AvaI and NcoI restriction endonucleases, and the DNA fragments were subjected to electrophoresis in a $0.8 \%$ agarose gel and transferred to a GeneScreen Plus nylon membrane (NEN Research Products). The copy number of the $m u r F$ gene was determined with a DNA probe that corresponded to the region from position 408 to position 1098 of the nucleotide sequence shown in Fig. 2. The DNA fragment was labelled with $\left[\alpha^{32} \mathrm{P}\right] \mathrm{dCTP}$ by nick translation. Hybridizations were carried out as described previously (Wada et al., 1992).

Northern blot hybridization. Isolation of total RNA from Synechocystis sp. PCC 6803 and Northern blot hybridization were carried out as described previously (Los et al., 1993). The DNA probe was the same as that used for Southern blot hybridization. The size of the murF mRNA was determined by reference to the mobilities of a set of RNA molecular mass markers (Boehringer Mannheim).

Complementation of a mutation in the murf gene in $E$. coli. Plasmids for the transformation of the murF-deficient strain of E. coli JE6607 were constructed as follows (see Fig. 4a). A plasmid designated pSA21 was obtained by subcloning the SmaI-ApaI fragment of 2837 bp from pSE17 (positions 23215158 ) into the corresponding sites of pBluescript II $\mathrm{KS}(+)$. Plasmids pSA216, pSA217, pSA2116, and pSA2118 were obtained after truncation of the $S$ maI-ApaI insert of pSA21 by exonuclease III and mung bean exonuclease. The sequences of the $5^{\prime}$ regions of the inserts were determined. Plasmid pAB92 was obtained by subcloning the $A p a I-S m a I$ fragment of $2789 \mathrm{bp}$ from pSE17. pEA13 was obtained by subcloning the ApaIEcoRI fragment of $2837 \mathrm{bp}$ from pSE17 into the analogous sites of pBluescript II $\mathrm{KS}(+)$. These plasmids were used for transformation of competent cells of the murF-deficient strain of E. coli JE6607. The resultant transformants were grown at $30^{\circ} \mathrm{C}$ on LB agar plates supplemented with $50 \mu \mathrm{g}$ ampicillin $\mathrm{ml}^{-1}$. Single colonies were transferred to $\mathrm{LB}$ agar plates without ampicillin.

The genetic complementation of the mutation in the murF gene in transformants was examined by monitoring the ability of the transformants to grow at $42^{\circ} \mathrm{C}$. The cells of the murF-deficient strain of E. coli JE6607 and the transformants were grown for $14-16 \mathrm{~h}$ at $30^{\circ} \mathrm{C}$ in liquid LB medium. Portions of the cultures were inoculated into $100 \mathrm{ml} \mathrm{LB}$ medium to give an $\mathrm{OD}_{660}$ of 0.015 at $30^{\circ} \mathrm{C}$, and these cultures were incubated at $42{ }^{\circ} \mathrm{C}$. The growth of the cells was followed by monitoring $\mathrm{OD}_{660}$.

\section{RESULTS}

\section{Organization of the murF-containing region of the genomic DNA of Synechocystis sp. PCC 6803}

We determined the nucleotide sequence of a $7490 \mathrm{bp}$ DNA fragment that is located downstream of the $\operatorname{des} A$ gene on the chromosome of Synechocystis sp. PCC 6803. Fig. 1 shows the genetic map of the DNA fragment. In addition to the previously cloned $\operatorname{des} A$ gene (Wada $e t$ al., 1990) five open reading frames were found in this region. ORF454 and ORF291 were located on the same strand as $\operatorname{des} A$, whereas ORF457, ORF128 and ORF172 were located on the opposite strand. ORF172 was previously identified as the rplI gene, which encodes the ribosomal protein L9 (Malakhov et al., 1993). ORF128 represents the cyt $M$ gene, which encodes a $c$-type cytochrome (Malakhov et al., 1994). ORF454 showed a high degree of homology to the murF gene of $E$. coli (Parquet et al., 1989) and was shown to be the equivalent of the murF gene in Synechocystis sp. PCC 6803, as described below. A search for sequence homology in the swiss-PROT and PIR databases did not reveal any significant similarity between ORFs 291 and 457 and known proteins.

Southern blot analysis revealed only one band that hybridized with the probe for the murF gene after digestion of the genomic DNA of Synechocystis sp. PCC 6803 with HindIII, DraI, AvaI and NcoI restriction endonucleases (data not shown). This result suggests that the murF gene exists as a single copy in the chromosome of Synechocystis sp. PCC 6803. The analysis of the copy numbers of the other ORFs in the vicinity of the murF gene (data not shown) revealed that they are also present as single-copy genes in Synechocystis sp. PCC 6803.

\section{Structural features of the murF gene}

The nucleotide sequence of the mur $F$ gene obtained from both strands and the deduced amino acid sequence are

\begin{tabular}{rrrrrrr}
$H$ & $D$ & $A$ & $N$ & $A$ & $D D N$ & 0 \\
1 & 1 & 1 & 1 & $A$ \\
\hline
\end{tabular}
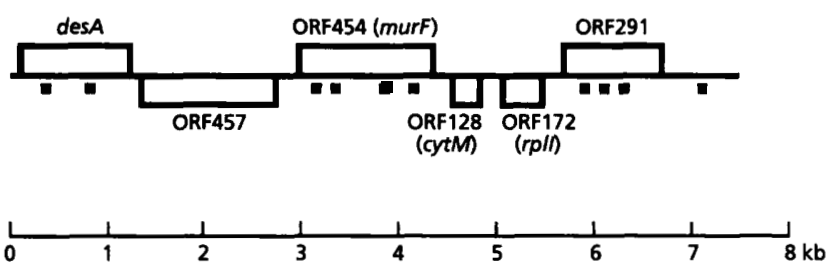

Fig. 1. A genetic map of the murf-containing region of the genomic DNA of Synechocystis sp. PCC 6803 . The highly iterated palindromic sequences GGCGATCGCC (HIP1) are indicated by solid boxes. The sites of recognition by the restriction endonucleases used for Southern blot analysis are shown: $A$, Aval; D, Dral; H, HindIII; N, Ncol. 
CGGAATAAAACCAGGATGTTTTTACTGGTCATTACTGGCTTCCGATTTTTCTGTATCTATTTCTCC TCCAATGTAAGTGATGCAAGCACCCATGGGAGGTGATCTAGATCACAGATAAAAATTGCAAATGAC TTAACATTCCTGAGTCAATTCTAACTCAGTTTTCCTCCGCCATATTTTTCACTCCTATTCTTTCCC ATGAACTCCAAACTTTCCCTATTTGACATCCGTACATTCCTAGAAAGTTGTCTATTGTCTGTTACC $\begin{array}{lllllllllllllllllllllll}M & N & S & K & L & S & L & F & D & I & R & T & F & L & E & S & C & L & L & S & V & T\end{array}$ AATCTTTCCGAGGATATACGGATAAATAATATTTGCACCGATACAAGATCTTTGGTGTCAGGGGAC $\begin{array}{lllllllllllllllllllllll}N & L & S & E & D & I & R & I & N & N & I & C & T & D & T & R & S & L & V & S & G & D\end{array}$ CTATTTCTTGCCTTGCGGGGGGAAAGTTTTGATGGCCATAGCTTCATTCCCCAGGCCTTGACGGCG $\begin{array}{lllllllllllllllllllllll}\text { L } & F & \text { L } & A & \text { L } & R & G & \text { E } & \text { S } & \text { F } & \text { D } & G & \text { H } & \text { S } & \text { F } & \text { I } & \text { P } & \text { Q } & \text { A } & \text { L } & \text { T } & \text { A }\end{array}$ GGGGCGATCGCCGTGGTGACGGATCGGCCAGTGGAGGGATTAGGGGAGACGGTGGCCCAATTTTTA $\begin{array}{lllllllllllllllllllllll}G & A & I & A & V & V & T & D & R & \text { P } & \text { V } & \text { E } & G & \text { L } & G & \text { E } & \text { T } & \text { V } & \text { A } & Q & \text { F } & L\end{array}$ GTGGAAGATACTTTGGTGGCCTATCAACACATCGCAGCGGGATGGCGACAACGGTTTACCATTCCC $\begin{array}{lllllllllllllllllllllll}V & E & D & T & L & V & A & Y & Q & H & I & A & A & G & W & R & Q & R & F & T & I & P\end{array}$ ATCATTGGGGTAACCGGTTCTGTGGGTAAGACCACCACCAAAGAATTAATTGCGGCGGTGTTGTCC $\begin{array}{lllllllllllllllllllllll}I & I & G & V & T & G & S & V & G & K & T & T & T & K & E & L & I & A & A & V & L & S\end{array}$ CAGTTTGGCAATGTGCATAAAACCAGAGCTAATTACAACAATGAAATTGGGGTGCCGAAAACTTTG $\begin{array}{lllllllllllllllllllllll}Q & F & G & N & \text { V } & \text { H } & \text { K } & \text { T } & R & \text { A } & \text { N } & \text { Y } & \text { N } & \text { N } & \text { E } & \text { I } & G & \text { V } & \text { P } & K & \text { K } & \text { L }\end{array}$ TTGGAACTATCCCCAGACCATGATTTTGCCATTGTGGAAATGGCCATGCGGGGTCGGGGGCAAATT $\begin{array}{llllllllllllllllllllll}L & E & L & S & P & D & H & D & F & A & I & V & E & M & A & M & R & G & R & G & Q & I\end{array}$ GCTCTTTTGGCGGATATTGCCAAGCCCACCATCGGTTTAATTACTAACGTTGGCACTGCCCACATT $\begin{array}{llllllllllllllllllllll}A & L & L & A & D & I & A & K & P & T & I & G & L & I & T & N & V & G & T & A & H & I\end{array}$ GGTCTTTTAGGCTCGGAGTTGGCGATCGCCGAAGCCAAGTGTGAATTACTAGCCCACCAACCGCCC $\begin{array}{llllllllllllllllllllll}G & L & L & G & S & E & L & A & I & A & E & A & K & C & E & L & L & A & H & Q & P & P\end{array}$ GAGAGCACCGCCATTCTCAATCGGGATAATGCTTTGTTAATGGAGACAGCCCAACGGTTTTGGCAG $\begin{array}{lllllllllllllllllllllll}E & S & T & A & I & L & N & R & D & N & A & L & L & M & E & T & A & Q & R & F & W & Q\end{array}$ GGAAAAACCATTACCTATGGCCTAGAAGGGGGAGATGTGCACGGGACAGTGGATGgGGAAAATTTA

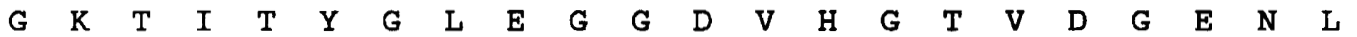
ATCCTTGATGGAGTTAGTTTGCCTTTGCCCCTAGCCGGTGTCCACAATGCCTCTAATTACCTAGCG $\begin{array}{llllllllllllllllllllll}I & L & D & G & V & S & L & P & L & P & L & A & G & V & H & N & A & S & N & Y & L & A\end{array}$ GCGATCGCCCTGGCCCAATGTTTAGGGTTGGACTGGCAGCAGTTACAGTCGGGGCTGACGGTGGAG $\begin{array}{llllllllllllllllllllll}A & I & A & L & A & \& & C & L & G & L & D & W & \& & \& & L & \& & S & G & L & T & V & E\end{array}$ TTACCCAAGGGGCGGGCCCGTCGTTACCAATGGGGCCAGGACGTGGTTCTATTGGATGAAACCTAT $\begin{array}{lllllllllllllllllllllll}\mathrm{L} & \mathrm{P} & \mathrm{K} & \mathrm{G} & \mathrm{R} & \mathrm{A} & \mathrm{R} & \mathrm{R} & \mathbf{Y} & \mathbf{Q} & \boldsymbol{W} & \mathrm{G} & \boldsymbol{Q} & \mathrm{D} & \mathrm{V} & \mathrm{V} & \mathrm{L} & \mathrm{L} & \mathrm{D} & \mathrm{E} & \mathrm{T} & \mathrm{Y}\end{array}$ AACGATGGCTTGGAATCCATGTTGGCATCCTTGGATTTATTGGCCAATACCCC'TGGGAAGCGACGT $\begin{array}{llllllllllllllllllllll}\mathbf{N} & D & G & L & E & S & M & L & A & S & L & D & L & L & A & N & T & P & G & K & R & R\end{array}$ TTAGCAGTGCTGGGGGCGATGAAGGAACTGGGAGATTATGGCCCGACATTTCACCAACGGGTGGGG $\begin{array}{llllllllllllllllllllll}\mathrm{L} & \mathrm{A} & \mathrm{V} & \mathrm{I} & \mathrm{G} & \mathrm{A} & \mathrm{M} & \mathrm{K} & \mathrm{E} & \mathrm{L} & \mathrm{G} & \mathrm{D} & \mathrm{Y} & \mathrm{G} & \mathrm{P} & \mathrm{T} & \mathrm{F} & \mathrm{H} & \mathrm{Q} & \mathrm{R} & \mathrm{V} & \mathrm{G}\end{array}$ GCCAAAGTGAAAGCCCTAGGTTTAGACGGTCTTTTCCTATTAGCCAATGATCCCAATACCGATGCC $\begin{array}{llllllllllllllllllllll}A & K & V & K & A & L & G & L & D & G & L & F & L & L & A & N & D & P & N & T & D & A\end{array}$ ATTGCCGCCGGGGCTAACGGTGTGGAGACCCAATCCTTCAGCGATGGGCCTAGTTTAGTGGCAGCC $\begin{array}{llllllllllllllllllllll}I & A & A & G & A & N & G & V & E & T & Q & S & F & S & D & G & P & S & I & V & A & A\end{array}$ CTAAAAACTACCCTCCAACCAGGCGATCGCCTCCTGTTTAAAGCATCCAATTCCGTCGGTCTAGGG $\begin{array}{llllllllllllllllllllll}\mathrm{L} & \mathrm{K} & \mathrm{T} & \mathrm{T} & \mathrm{L} & \mathrm{Q} & \mathrm{P} & \mathrm{G} & \mathrm{D} & \mathrm{R} & \mathrm{L} & \mathrm{L} & \mathbf{F} & \mathrm{K} & \mathrm{A} & \mathbf{S} & \mathbf{N} & \mathbf{S} & \mathrm{V} & \mathrm{G} & \mathrm{L} & \mathrm{G}\end{array}$ GCTGTGGTCAGTCAGTTGTTGGCAGAAAATCCCACTTCGGTTTAAAACGGCAAGGCTTGAGTCAGT $\begin{array}{lllllllllllllll}A & V & V & S & Q & L & L & A & E & N & P & T & S & V & *\end{array}$

shown in Fig. 2. The murF gene encodes a protein of 454 amino acid residues with a predicted molecular mass of $48 \mathrm{kDa}$ and a calculated $\mathrm{pI}$ of $4 \cdot 9$. These characteristics are similar to those of the protein from E. coli, which has a predicted molecular mass of $48 \mathrm{kDa}$ and a calculated $\mathrm{pI}$ of 5.3. The 5' flanking region of the murF gene of Synecbocystis 


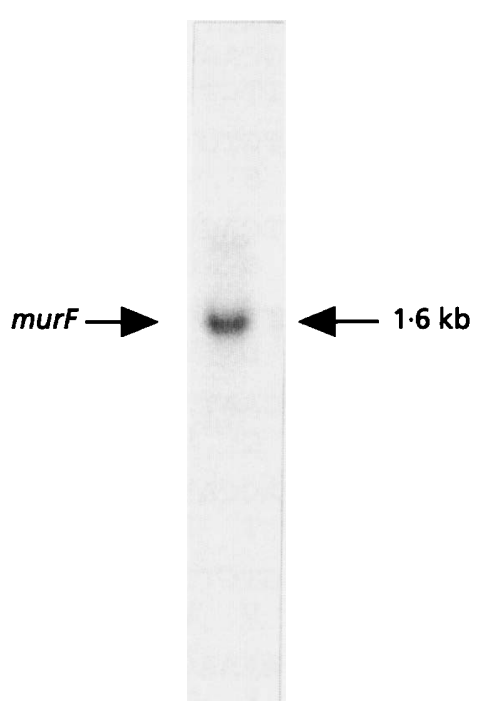

Fig. 3. Northern blot analysis of the expression of the murF gene in Synechocystis sp. PCC 6803.

sp. PCC 6803 does not contain any sequence motifs that resemble the regulatory sequences found in most genes from E. coli, such as the $-35,-10$, and Shine-Dalgarno motifs.

The details of the nucleotide sequence of the murF gene of Synechocystis sp. PCC 6803 are unique in that this gene contains four palindromic GGCGATCGCC motifs (double-underlined in Fig. 2). The murF gene of E. coli
(Parquet et al., 1989) does not contain such sequences. This palindromic sequence appears ten times in the 7490 bp fragment of the genomic DNA of Synechocystis sp. PCC 6803 (Fig. 1).

\section{Northern blot analysis of the expression of the murF gene}

Total RNA from Synechocystis sp. PCC 6803 was subjected to Northern blot hybridization with the probe for the murF gene. Only one specifically-hybridizing band appeared, with the mobility of a $1.6 \mathrm{~kb}$ fragment (Fig. 3), indicating that the murF gene is transcribed as a monocistronic operon. The upper bands represent nonspecific hybridization of the probe to the rRNAs. This result coincides with the finding that the murF gene is located as a non-clustered single gene on the chromosome of Synechocystis sp. PCC 6803 (Fig. 1). We examined alterations in the level of the murF transcript upon incubation of the cells of this strain at low and high temperatures and upon incubation in the dark and in the light at various light intensities. Under all the conditions tested, the intensity of the hybridized band that corresponded to the $m u r F$ gene remained at a constant level (data not shown). This result implies that the murF gene is transcribed constitutively in the cells of Synechocystis sp. PCC 6803.

\section{Complementation of a temperature-sensitive mutation in the murf gene of $E$. coli by the murF gene of Synechocystis Sp. PCC 6803}

To characterize in further detail the product of the $m u r F$ gene of Synechocystis sp. PCC 6803, we transformed cells of (a)

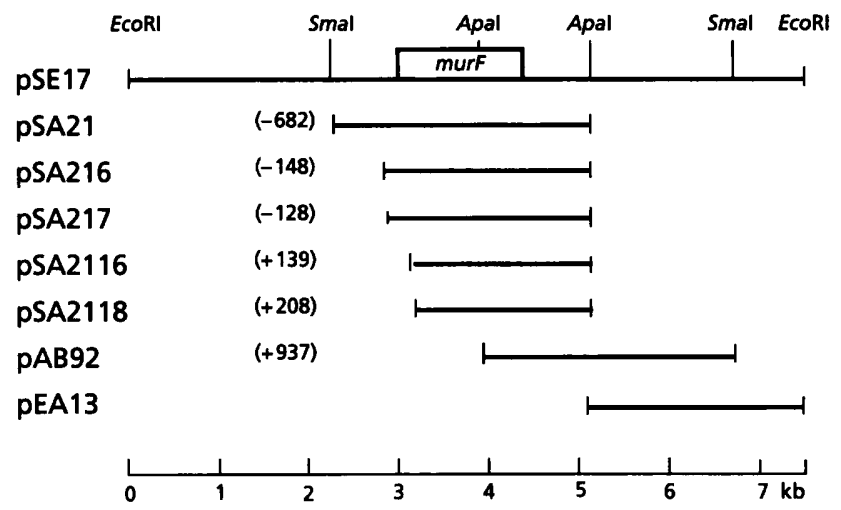

\begin{tabular}{|c|}
\hline $\begin{array}{c}\text { Results of } \\
\text { complementation } \\
\text { test }\end{array}$ \\
\hline Positive \\
Positive \\
Positive \\
Positive \\
Negative \\
Negative \\
Negative \\
Negative \\
\hline
\end{tabular}

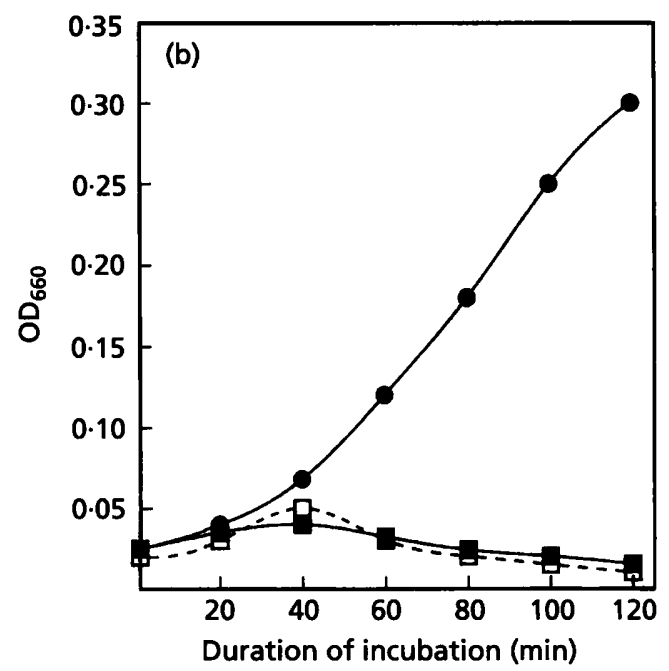

Fig. 4. Complementation of mutation in the murF gene in E. coli strain JE6607 by the murF gene from Synechocystis sp. PCC 6803. (a) Deletion map of the murF-containing chromosomal region of Synechocystis sp. PCC 6803 , indicating the fragments of DNA used for genetic complementation of the temperature-sensitive murF mutant of $E$. coli. Numbers in parentheses indicate positions from the initiation codon $(+1)$ of the murF gene. 'Positive' and 'Negative' indicate positive and negative results of complementation. The sites recognized by the restriction endonucleases that were used for subcloning are shown. (b) Growth at $42{ }^{\circ} \mathrm{C}$ of various transformants of $E$. coli JE6607. $\square$, murF-deficient mutant cells of $E$. coli JE6607 (control); ${ }^{2}$, cells transformed with pSA2116; O, cells transformed with pSA217. Cells transformed with pSA2118, pAB92 and pEA13 gave essentially the same results as cells transformed with pSA2116. Cells transformed with pSE17, pSA21 and pSA216 gave essentially the same results as cells transformed with pSA217. 
a murF-deficient mutant of E. coli JE6607 (Maruyama et al., 1988) with plasmids that carried a full-length or truncated murF gene from Synechocystis sp. PCC 6803. Since the cells of this strain of $E$. coli are unable to synthesize intact cell walls, they form colonies with mucoid shape at $30^{\circ} \mathrm{C}$, and they lyse at $42^{\circ} \mathrm{C}$.

The plasmids used for the transformation of $E$. coli JE6607 are shown in Fig. 4(a). The control plasmids pBluescript II KS $(+)$ and pEA13, which contained none of the murF sequence, did not restore the ability to grow at $42{ }^{\circ} \mathrm{C}$ (Fig. 4b). The transformation of the $E$. coli mutant with plasmids pSE17, pSA21, pSA216 and pSA217 which carried the full-length murF gene resulted in colonies with regular morphology. The transformed cells grew at $42{ }^{\circ} \mathrm{C}$ as did the wild-type cells (Fig. 4b). Plasmids pSA2116, pSA2118, and pAB92 with truncated mur $F$ genes did not complement the temperature-sensitive phenotype of the mutant cells (Fig. 4b). All these results indicate that the murF gene of Synechocystis sp. PCC 6803 was recognized and expressed by the transcriptional and translational machinery of $E$. coli, and that the product of the murF gene catalysed the ligation of $D$ Ala-D-Ala to UDP-N-acetylmuramoyl-L-Ala-D-Glu-mesodiaminopimelate (Michaud et al., 1987). Although the murF gene of Synechocystis sp. PCC 6803 does not have any sequence motifs that resemble the regulatory elements found in the analogous gene from E. coli (Fig. 2), it was expressed in $E$. coli without a requirement for any additional regulatory sequence.

\section{DISCUSSION}

We cloned the murF gene, which encodes UDP-Nacetylmuramoyl-L-alanyl-D-glutamyl-meso-2,6-diaminopimeloyl-D-Ala-D-Ala synthetase (EC 6.3.2.15), the enzyme that participates in the synthesis of murein, from the cyanobacterium Synecbocystis sp. PCC 6803. The organization of the genomic region that includes the murF gene in Synechocystis sp. PCC 6803 differs from that of the murF-containing fragment of the $E$. coli chromosome.

The clustered organization of genes involved in the synthesis of murein and cell division has been well documented in E. coli and in other eubacteria (Kröger et al., 1991; Mengin-Lecreulx et al., 1989). However, the chromosome of Synechocystis sp. PCC 6803 seems to be organized in a different way. We have not found any other genes for the enzymes that are involved in the synthesis of murein in the vicinity of the murF gene of Synecbocystis sp. PCC 6803 (Fig. 1). The rplI gene was also found to be a single-gene operon in Synechocystis sp. PCC 6803 (Malakhov et al., 1993), whereas the rplI gene is a member of a cluster of genes for ribosomal proteins of $E$. coli (Schnier et al., 1986).

A novel structural feature of the murF gene of Synechocystis sp. PCC 6803 is the presence of four palindromic sequences, GGCGATCGCC, in its coding region (Figs 1 and 2). The murF gene of $E$. coli does not contain any copies of this sequence. We performed computer analysis to examine the appearance of such sequences in the
EMBL prokaryotic database, and we found that the palindrome RGCGATCGCY appears in cyanobacterial genomes ten times more frequently than in genomes of other prokaryotes. We suspect that this structural feature has a specific function in cyanobacteria and that it is probably relevant to DNA restriction and DNA modification systems. Recently, Gupta et al. (1993) suggested that the octanucleotide GCGATCGC, i.e. the highly iterated palindrome 1 (HIP1), is involved in recombination in Synechococcus sp. PCC 6301.

Alignment of the amino acid sequences of the mur $F$ genes from Synechocystis sp. PCC 6803 and E. coli revealed $39 \%$ identity at the amino acid level (Fig. 5). Three highly homologous regions were found in the sequences: at positions 35-55, 115-155 and 273-290 (boxed in Fig. 5). The function of the first region between positions 35 and 55 is unknown. The second region between positions 115 and 155 includes a typical ATP-binding domain GxxGKT/S (Parquet et al., 1989) and it may possibly be the active site of the enzyme. The region corresponding to amino acid residues $273-290$ is also conserved to a considerable extent in UDP- $N$-acetylmuramoyl-dipeptide synthetase, which is the product of the murD gene of $E$. coli (Ikeda et al., 1990; Mengin-Lecreulx et al., 1989; Mengin-Lecreulx \& van Heijenoort, 1990). This region may represent the binding site of such proteins to the UDP-N-acetylmuramoyl-monopeptide or -tripeptide.

The transformation of murF-deficient cells of $E$. coli JE6607 with the cyanobacterial murF gene restored the normal phenotype of $E$. coli cells and allowed them to survive and proliferate at high temperature. The cyanobacterial murF gene was expressed in E. coli, although no part of the murF gene of Synechocystis sp. PCC 6803 exhibited any sequence similarity to prokaryotic regulatory motifs.

Moreover, no sequence homologous to a ribosomebinding site (Shine-Dalgarno motif) was found in the vicinity of the initiation codon of the $m u r F$ gene of Synechocystis sp. PCC 6803, while the murE-murF operon of $E$. coli does contain a typical Shine-Dalgarno motif (Mengin-Lecreulx et al., 1989; Tao \& Ishiguro, 1989; Michaud et al., 1990). Nevertheless, the cyanobacterial gene was effectively expressed in E. coli.

It has been reported that several cyanobacterial genes lack a typical Shine-Dalgarno motif (McCarn et al., 1988; Tandeau de Marsac \& Houmard, 1987). The absence of such sequences cannot be explained by the unusual structure of the mRNA-binding region of the 16S rRNA in cyanobacteria. Indeed, the mRNA-binding region of the $16 \mathrm{~S}$ rRNA of a filamentous cyanobacterium, Anabaena sp. PCC 7120, is very similar to that of E. coli (Ligon et al., 1991). The fact that the murF gene from Synechocystis sp. PCC 6803 can be expressed in E. coli suggests that a Shine-Dalgarno sequence is not a prerequisite for the translation of some mRNAs, and that some other factors may be able to substitute for this sequence. However, there are several reports of fruitless attempts to express cyanobacterial genes in $E$. coli under the control of their 
6803 GAIAVVTDRPVEGLGETVAQFLVEDTLVAYQHIAAGW-RQRFTIPIIGV TGSVGKTTTKELIAAVLSQF

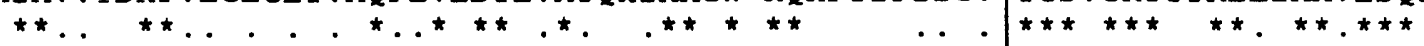

E.c. AAGALLVSRPLD-I-D-LPQLIVKDTRLAFGELAA-WVRQQVPARVVAL TGSSGKTSVKEMTAAILSOC

II

6803 GNVHKTRANYNNEIGVPKTLL ELSPDHDFAIVEMAMRGRGQIALLADIAKPTIGLITNVGTAHIGLLGS

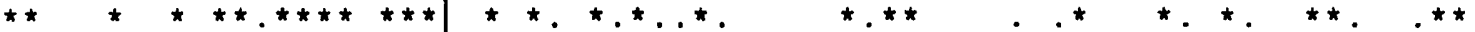

E.c. GNTLYTAGNLNNDIGVPMTLL RLTPEYDYAVIELGANHQGEIAWTVSLTRPERALVNNLAAAHLEGFGS

6803 ELAIAEAKCELLAHQP PESTAILNRDNA-LLM-ET- -AQR-FWQ-G-KTITYGLEGGDVHGTVDGENLIL

6803 YNDGLESMLASLDLLANT PGKRRLAVLGAMKELGDYGPTFHQRVGAKVKALGLDGLFLLANDPNTDAIAA

6803 GANGVETQSFSDGPSLVAALKTTL--QPGDRLLFKASNSVGLGAVVSQLLAENPTSV

Fig. 5. Alignment of the amino acid sequences of the products of translation of the murF genes of Synechocystis sp. PCC 6803 (6803) and E. coli (E.C.; Parquet et al., 1989). Asterisks indicate identical amino acids and dots indicate homologous amino-acid replacements. Highly conserved regions are boxed.

own regulatory sequences (Tandeau de Marsac \& Houmard, 1987). Such problems were overcome by use of artificial promoters and ribosome-binding sites (Wada $e t$ al., 1993).

The deletion analysis of the plasmids that carried the murF gene of Synechocystis sp. PCC 6803 showed that the $128 \mathrm{bp}$ $5^{\prime}$ upstream region of the gene (positions -128 to +1 , counting from the first ATG codon) contains all the necessary elements for the expression of the murF gene in E. coli (Fig. 4).

\section{ACKNOWLEDGEMENTS}

We are grateful to Dr T. Sakamoto for the subcloning of the fragment of Synechocystis sp. PCC 6803 genomic DNA from pTZ19R into the pBluescript vector and to Dr I. N. Maruyama for help in obtaining the murF-deficient mutant of E. coli. This work was supported, in part, by Grants-in-Aid for Scientific Research on Priority Areas (nos 04273102 and 04273103) to N.M. from the Ministry of Education, Science and Culture, Japan. D.A.L. was supported by a post-doctoral fellowship from the Japanese Society for the Promotion of Science.

\section{REFERENCES}

Cooper, S. (1991). Synthesis of the cell surface during the division cycle of rod-shaped, gram-negative bacteria. Microbiol Rev 55, 649-674.

Drews, G. \& Weckesser, J. (1982). Function, structure and composition of cell walls and external layers. In The Biology of Cyanobacteria, pp. 333-357. Edited by N. G. Carr \& B. A. Whitton. Oxford: Blackwell Scientific Publications.

Gupta, A., Morby, A. P., Turner, J. S., Whitton, B. A. \& Robinson, N. J. (1993). Deletion within the metallothionein locus of cadmiumtolerant Synechococcus PCC6301 involving a highly iterated palindrome (HIP1). Mol Microbiol 7, 189-195.

Ikeda, M., Wachi, M., Ishino, F. \& Matsuhashi, M. (1990). Nucleotide sequence involving $m u r D$ and an open reading frame ORF-Y spacing murF and fts $W$ in Escherichia coli. Nucleic Acids Res 18, 1058.

Jürgens, U. J. \& Weckesser, J. (1986). Polysaccharide covalently linked to the peptidoglycan of the cyanobacterium Synechocystis sp. strain PCC6714. J Bacteriol 168, 568-573.

Jürgens, U. J., Drews, G. \& Weckesser, J. (1983). Primary structure of the peptidoglycan from the unicellular cyanobacterium Synechocystis sp. strain PCC6714. J Bacteriol 154, 471-478. 
Jürgens, U. J., Golecki, J. R. \& Weckesser, J. (1985). Characterization of the cell wall of the unicellular cyanobacterium Synechocystis PCC6714. Arch Microbiol 142, 168-174.

Kröger, M., Wahl, R. \& Rice, P. (1991). Compilation of DNA sequences of Escherichia coli (update 1991). Nucleic Acids Res 19 (Suppl.), 2023-2043.

Ligon, P. J. B., Meyer, K. G., Martin, J. A. \& Curtis, S. E. (1991). Nucleotide sequence of a $16 \mathrm{~S}$ rRNA gene from Anabaena sp. strain PCC 7120. Nucleic Acids Res 19, 4553.

Los, D. A., Horvath, I., Vigh, L. \& Murata, N. (1993). The temperature-dependent expression of the desaturase gene $\operatorname{des} A$ in Synechocystis PCC6803. FEBS Lett 318, 57-60.

Lugtenberg, E. J. J. \& van Schijndel-van Dam, A. (1972). Temperature-sensitive mutants of Escherichia coli K-12 with low activity of the L-alanine adding enzyme and the $\mathrm{D}$-alanyl-D-alanine adding enzyme. $J$ Bacteriol 110, 35-40.

Malakhov, M. P., Wada, H., Los, D. A., Sakamoto, T. \& Murata, N. (1993). Structure of a cyanobacterial gene encoding the $50 \mathrm{~S}$ ribosomal protein L9. Plant Mol Biol 21, 913-918.

Malakhov, M. P., Wada, H., Los, D. A., Semenenko, V. E. \& Murata, N. (1994). A new type of cytochrome $c$ from Synechocystis PCC6803. J Plant Pbysiol 144 (in press).

Maruyama, I. N., Yamamoto, A. H. \& Hirota, Y. (1988). Determination of gene products and coding regions from the murE-murF region of Eschericbia coli. J Bacteriol 170, 3786-3788.

McCarn, D. F., Whitaker, R. A., Alam, J., Vrba, J. M. \& Curtis, S. E. (1988). Genes encoding the alpha, gamma, delta, and four $F_{0}$ subunits of ATP synthase constitute an operon in the cyanobacterium Anabaena sp. strain PCC7120.J Bacteriol. 170, 3448-3458.

Mengin-Lecreulx, D. \& van Heijenoort, J. (1990). Nucleotide sequence of the murD gene encoding the UDP-MurNAc-L-Ala-DGlu synthetase of Escherichia coli. Nucleic Acids Res 18, 183.

Mengin-Lecreulx, D., Parquet, C., Desviat, L. R., Pla, J., Flouret, B., Ayala, J. A. \& van Heijenoort, J. (1989). Organization of the murEmurG region of Escherichia coli: identification of the murD gene encoding the D-glutamic-acid-adding enzyme. $J$ Bacteriol 171, 6126-6134.

Michaud, C., Blanot, D., Flouret, B. \& van Heijenoort, J. (1987). Partial purification and specificity studies of the D-glutamateadding and D-alanyl-D-alanine-adding enzymes from Escherichia coli K12. Eur J Biochem 166, 631-637.

Michaud, C., Parquet, C., Flouret, B., Blanot, D. \& van Heijenoort, J. (1990). Revised interpretation of the sequence containing the murE gene encoding the UDP- $N$-acetylmuramyl-tripeptide synthetase of Escherichia coli. Biochem J 269, 277-280.

Needleman, S. B. \& Wunsch, C. D. (1970). A general method applicable to the search for similarities in the amino acid sequence of two proteins. $J$ Mol Biol 48, 443-453.
Parquet, C., Flouret, B., Mengin-Lecreulx, D. \& van Heijenoort, J. (1989). Nucleotide sequence of the murF gene encoding the UDPMurNAc-pentapeptide synthetase of Escherichia coli. Nucleic Acids Res 17, 5379.

Rogers, H. J., Perkins, H. R. \& Ward, J. B. (1980). Biosynthesis of peptidoglycan. In Microbial Cell Walls and Membranes, pp. 239-297. London: Chapman \& Hall.

Sambrook, J., Fritsch, E. F. \& Maniatis, T. (1989). Molecular Cloning: a Laboratory Manual, 2nd edn. Cold Spring Harbor, NY: Cold Spring Harbor Laboratory Press.

Sanger, F., Nicklen, S. \& Coulson, A. R. (1977). DNA sequencing with chain-terminating inhibitors. Proc Natl Acad Sci USA 74, 5463-5467.

Schnier, J., Kitakawa, M. \& Isono, K. (1986). The nucleotide sequence of an Escberichia coli chromosomal region containing the genes for ribosomal proteins S6, S18, L9 and an open reading frame. Mol \& Gen Genet 204, 126-132.

Stanier, R. Y., Kunizawa, R., Mandel, M. \& Cohen-Bazire, G. (1971). Purification and properties of unicellular blue-green algae (order Chroococcales). Bacteriol Rev 35, 171-202.

Tandeau de Marsac, N. \& Houmard, J. (1987). Advances in cyanobacterial molecular genetics. In The Cyanobacteria, pp. 251302. Edited by P. Fay \& C. van Baalen. Amsterdam: Elsevier.

Tao, J.-S. \& Ishiguro, E. E. (1989). Nucleotide sequence of the murE gene of Escherichia coli. Can J Microbiol 36, 1051-1054.

Wada, H. \& Murata, N. (1989). Synechocystis PCC6803 mutants defective in desaturation of fatty acids. Plant Cell Pbysiol 30, 971-978.

Wada, H., Gombos, Z. \& Murata, N. (1990). Enhancement of chilling tolerance of a cyanobacterium by genetic manipulation of fatty acid desaturation. Nature 347, 200-203.

Wada, H., Gombos, Z., Sakamoto, T. \& Murata, N. (1992). Genetic manipulation of the extent of desaturation of fatty acids in membrane lipids in the cyanobacterium Synechocystis PCC6803. Plant Cell Pbysiol 33, 535-540.

Wada, H., Avelange-Macherel, M.-H. \& Murata, N. (1993). The $\operatorname{des} A$ gene of the cyanobacterium Synechocystis PCC6803 is the structural gene for $\Delta 12$ desaturase. J Bacteriol 175, 6056-6058.

Weckesser, J. \& Jurgens, U. J. (1988). Cell walls and external layers. Methods Enzymol 167, 173-188.

Williams, J. G. K. (1988). Construction of specific mutations in photosystem II photosynthetic reaction center by genetic engineering methods in Synechocystis 6803. Methods Envymol 167, 766-778.

Received 18 July 1994; accepted 19 September 1994. 